\title{
FACTORS INFLUENCING THE LEVEL OF PATIENT'S SATISFACTION WITH AUGMENTATION MAMMAPLASTY
}

\author{
Zayakova Y. ${ }^{1}$, I. Aleksandrov ${ }^{2}$ \\ ${ }^{1}$ Department of Burns, Plastic and Aesthetic Surgery, Naval Hospital of Varna, \\ Military Medical Academy of Sofia, \\ ${ }^{2}$ Department of Psychiatry and Medical Psychology, St. Marina University Hospital of Varna, \\ Medical University of Varna
}

\begin{abstract}
This paper investigated the degree of women's satisfaction with the outcome of the augmentation mammaplasty and the capacity of clear-cut criteria to judge the postoperative level of satisfaction. The analysis included 96 women aged 20-40 years who had undergone augmentation mammaplasty during the period from 2001 till 2011. The investigation was carried out 6 months after the operation during the postoperative examinations by filling-in a questionnaire about the level of satisfaction with the surgery. The following statistical methods are used: descriptive statistics, testing the internal consistency of the scales with Cronbach's Alpha, correlation and regression analyses. Data processing was performed by using SPSS-19 statistical package. Some specific interrelations between different parameters that measured the level of satisfaction were determined. The calculated multiple correlation coefficient of independent and dependent variables was of $r=0,678$ which was a very good result. The proportion of variation in the dependent variable is $\mathbf{r}^{2}=0,522$. The assessment of the new appearance after surgery was most strongly influenced by patients' improved function in everyday activities such as work, social relationships, leisure, and sex. The multiple correlation coefficient was $r=0,686$ and the proportion of variation in the dependent variable was $r^{2}=0,519$. This phenomenon could be related to the proactive seeking and receiving feedback, and the assessment of the surgery is mostly determined by that feedback. The analysis of the factors influencing the levels of satisfaction with augmentation mammaplasty provided a valuable feedback for the surgeons. Obviously, the general assessment score of the surgical work is quite high.
\end{abstract}

Key words: augmentation mammaplasty, satisfaction, questionnaire, personal assessment, Cronbach's Alpha

\section{INTRODUCTION}

Modern women have become increasingly demanding towards their physical appearance and try their best to look and feel beautiful according to their own aesthetic criteria. For that reason many women undergo plastic surgery to perfect their physical appearance.

This paper investigates the degree of women's satisfaction with the outcome of the augmentation mammaplasty and the capacity of clear-cut criteria to judge the postoperative level of satisfaction. Current research shows that patients differ significantly in their expressed level of satisfaction substantially on that issue $(5,6)$.

Some women who request augmentation are more interested in the quantative change after surgery as their primary concern is a size alteration whereas others view the desired

Address for correspondence

Y. Zayakova, Dept. of Burns, Plastic and Aesthetic Surgery, Naval Hospital of Varna, Military Medical Academy of Sofia

3 Hristo Smirnenski Str., Varna 9010, Bulgaria

e-mail: zayakova@yahoo.com change in their body in terms of achieving overall proportions and qualitative change $(2,4)$.

From an aesthetic point of view, breasts are one of the most attractive features of the female anatomy. Therefore, many women strive to achieve a better look and attempt to correct the shape and size of their breasts. In cases such as breast hypoplasia, congenital asymmetry, or ptosis, with advancing age women suffer from emotional and psychological trauma manifested in social inadaptability and depressive moods related to inferiority complex (10). In the past, women did not usually regard small variations in breast shape and size as a significant problem. Nowadays the modern image of ideal beauty and symmetry has a great impact on women's decision to aspire after perfect body and that results in an increasing number of cosmetic breast surgery. In these women's view, such augmentation is intended to provide not only the desired new look, but also a boost of confidence and better overall quality of life $(8,9,11)$.

Recent research in the field of plastic and aesthetic surgery outlines the various aspects of satisfaction with the surgery in social, professional and private life $(3,12)$. 
Investigating the levels of satisfaction with the outcome of surgery could be carried out using the assessments methods of psychology (7). The objective criteria for the quality of the surgical work involve not only the successful outcome according to the surgeon, but also the subjective level of satisfaction of the patients who feel, if satisfied, more confident and empowered (1).

The concept of satisfaction can be viewed in two dimensions: overt, manifested in the social relationships and public life, and covert, in private life and feeling of self-satisfaction (1).

The contemporary assessment of the surgical work involves not only the efficiency of the procedure, but its effectiveness in terms of patient's satisfaction with the result. Here the study adheres to the understanding that efficiency refers to the surgical performance, while effectiveness is focused on the patient's feeling of satisfaction with the outcome.

The aim of our study is to examine the different aspects and levels of satisfaction with augmentation mammaplasty. Thus the following requirements need to be met: i) presentation of data describing various aspects of satisfaction, ii) analysis of the interdependence between the various parameters of satisfaction, and iii) identification of the relative influence of each parameter in the overall distribution of satisfaction levels. ternal consistency varied from 0,71 to 0,83 for the different scales and met the needs of the present study. The following statistical methods were used: descriptive statistics, testing the internal consistency of the scales with Cronbach's Alpha, correlation and regression analyses. Data processing was performed by using SPSS-19 statistical package.

\section{RESULTS AND DISCUSSION}

The assessment parameters of the physical appearance of the breasts involved, on one hand, specific assessments related to the shape, softness, volume, symmetry of the breasts, scars, feeling of body comfort while wearing clothes, in a swimming costume, and naked, the opinion of the husband and family, friends and colleagues as well. On the other hand, we introduced more general parameters of satisfaction with the overall physical appearance, confidence and self-esteem. The objective of the analysis was to determine specific interrelations between different parameters that measured the level of satisfaction. Our results were summarized in seven tables.

The results from the descriptive statistical analysis of satisfaction parameters are demonstrated on Table 1.

The present descriptive statistics showed the overall level

Table 1. Descriptive statistics of the parameters of the levels of satisfaction with the surgery

\begin{tabular}{||l|c|c|c|c|c|c|c|c|c|c|c|c||}
\hline \hline & $\mathbf{1}$ & $\mathbf{2}$ & $\mathbf{3}$ & $\mathbf{4}$ & $\mathbf{5}$ & $\mathbf{6}$ & $\mathbf{7}$ & $\mathbf{8}$ & $\mathbf{9}$ & $\mathbf{1 0}$ & $\mathbf{1 1}$ & $\mathbf{1 2}$ \\
\hline Number of patients & 96 & 96 & 96 & 96 & 96 & 96 & 96 & 96 & 96 & 96 & 96 & 96 \\
\hline Average value & 22,6 & 11,41 & 22,96 & 22,59 & 22,01 & 19,01 & 14,06 & 3,36 & 3,635 & 3,343 & 3,531 & 3,343 \\
\hline Standard deviation & 1,96 & 1,358 & 2,149 & 2,986 & 3,354 & 1,744 & 3,821 & 0,617 & 0,545 & 0,856 & 0,71 & 0,765 \\
\hline Minimum & 15 & 4 & 15 & 6 & 11 & 13 & 7 & 2 & 2 & 1 & 1 & 1 \\
\hline Maximum & 24 & 12 & 24 & 24 & 24 & 20 & 20 & 4 & 4 & 4 & 4 & 4 \\
\hline \hline
\end{tabular}

Legend:

1. Assessment of the outcome in terms of shape, softness, volume, symmetry of the breasts and scars (AOSHVSS)

2. Level of functioning and activities - sex, leisure, social relationships, work (LFA)

3. Feeling comfortable in situations while wearing ( $F W W)$

4. Feeling comfortable in situations where a bathing suit (FCWB)

5. Feeling comfortable in situations when naked (FCWN)

6. Assessment of the effect of surgery by a spouse or friend, relatives, colleagues, family (AESF)

7. Degree of importance of breast size itself to surgery, her husband nearby (DIBS)

8. To what extent has the surgery changed your life?

9. Assessment of the new appearance.

10. Do you feel the difference in your appearance before and after the surgery?

11. Level of satisfaction with the new appearance.

12. Do you think that your new appearance has boosted your confidence and self-esteem?

\section{MATERIAL AND METHODS}

The analysis included 96 women aged 20-40 years who had undergone augmentation mammaplasty during the period from 2001 till 2011. The investigation was carried out 6 months after the operation during the postoperative examinations by filling-in a questionnaire about the level of satisfaction with the surgery. Cronbach's alpha index of in- of satisfaction with the surgery in psychosocial context (Tables 2, 3, and 4).

The correlation between the different assessment parameters allows a more precise analysis of how they relate to which other and which one prevails when assessing the surgery outcome and the level of satisfaction. For this purpose, regression analysis was applied (Table 5). 
Table 2. Frequency distributions of the parameter 'Evaluation of the new appearance'

\begin{tabular}{||c|c|c||}
\hline \hline \multirow{2}{*}{ Parameter patterns } & \multicolumn{2}{|c||}{ Patients } \\
\cline { 2 - 3 } & $\mathrm{n}$ & $\%$ \\
\hline Not very poor & 3 & 3,12 \\
\hline Good & 29 & 30,21 \\
\hline Very good & 64 & 66,67 \\
\hline Total & 96 & 100,00 \\
\hline \hline
\end{tabular}

Table 3. Frequency distributions of the parameter 'Satisfaction with the new appearance'

\begin{tabular}{||l|c|c||}
\hline \hline \multirow{2}{*}{ Patient's satisfaction } & \multicolumn{2}{|c||}{ Patients } \\
\cline { 2 - 4 } & $\mathrm{n}$ & $\%$ \\
\hline I am not satisfied & 2 & 2,08 \\
\hline $\begin{array}{l}\text { I am somewhat } \\
\text { satisfied }\end{array}$ & 6 & 6,255 \\
\hline I am satisfied & 27 & 28,13 \\
\hline I am very satisfied & 61 & 63,54 \\
\hline Total & 96 & 100,00 \\
\hline \hline
\end{tabular}

Table 4. Frequency distributions of the parameter 'Self-confidence'. Has the operation increased your

\begin{tabular}{||l|c|c||}
\hline \multirow{2}{*}{ Patient's self-confidence } & \multicolumn{2}{|c||}{ Patients } \\
\cline { 2 - 3 } & $\mathrm{n}$ & $\%$ \\
\hline I don't think so & 3 & 3,12 \\
\hline To a certain degree & 8 & 8.3 \\
\hline Yes & 38 & 39.6 \\
\hline Very much & 47 & 49 \\
\hline Total & 96 & 100,00 \\
\hline \hline
\end{tabular}

Table 5. Variables included in the regression model

\begin{tabular}{||l|c||}
\hline \hline Independent variables & Dependent variables \\
\hline 1. AOSHVSS & $\begin{array}{r}\text { Assessment of the new appearance } \\
\text { (ANA) }\end{array}$ \\
\hline 2. LFA & $\begin{array}{r}\text { Satisfaction with the new appearance } \\
\text { (SNA) }\end{array}$ \\
\hline 3. FWW & Confidence (C) \\
\hline 4. FCWB & \\
\hline 5. FCWN & AESF \\
\hline 7. DIBS & \multicolumn{2}{|c|}{} \\
\hline \hline
\end{tabular}

Quite commonly in science, each parameter is influenced by many different factors, i.e. one dependent variable relates to several independent ones. Each separate independent variable exerts different influence on the dependent variable.

The calculated multiple correlation coefficient of independent and dependent variables is of $r=0,678$ which is a very good result. The proportion of variation in the dependent variable is $r^{2}=0,522$ (Table 6).

Table 6. Impact level of the independent variables on the dependent variable (ANA)

\begin{tabular}{|l|c|c|c||}
\hline $\begin{array}{l}\text { Independent } \\
\text { variables }\end{array}$ & $\boldsymbol{t}$ & $\begin{array}{c}\text { Standardized } \\
\text { beta }\end{array}$ & $\mathbf{p}$ \\
\hline 1. AOSHVSS & 0,293 & 0,032 & 0,77 \\
\hline 2. LFA & 2,492 & 0,228 & 0,015 \\
\hline 3. FWW & $-0,675$ & $-0,083$ & 0,502 \\
\hline 4. FCWB & 2,233 & 0,327 & 0,018 \\
\hline 5. FCWN & 1,055 & 0,128 & 0,294 \\
\hline 6. AESF & 0,775 & 0,093 & 0,44 \\
\hline 7. DIBS & 1,837 & 0,165 & 0,02 \\
\hline \hline
\end{tabular}

As evident from these results, the assessment of the new appearance after surgery is most strongly influenced by patients' improved function in everyday activities such as work, social relationships, leisure, and sex.

This phenomenon could be related to the proactive seeking and receiving feedback, and the assessment of the surgery is mostly determined by that feedback.

The second strongest factor influencing on the assessment is related to the feeling of comfort and confidence when the client is wearing a swimming costume. The swimsuit is the most scarce public dress and, wearing it, the client shows her new appearance amongst the wider public (Table 7). The multiple correlation coefficient is $\mathrm{r}=0,686$ and the proportion of variation in the dependent variable is $r^{2}=0,519$.

Table 7. Impact level of the independent variables on the dependent variable/satisfaction with the new appearance (SNA)

\begin{tabular}{|l|c|c|c||}
\hline \hline $\begin{array}{l}\text { Independent } \\
\text { variables }\end{array}$ & $\boldsymbol{t}$ & Standardized beta & $\mathbf{p}$ \\
\hline 1. AOSHVSS & 2,826 & 0,282 & 0,006 \\
\hline 2. LFA & 0,631 & 0,052 & 0,53 \\
\hline 3. FWW & 0,331 & 0,037 & 0,741 \\
\hline 4. FCWB & 2,004 & 0,266 & 0,02 \\
\hline 5. FCWN & $-1,103$ & $-0,121$ & 0,273 \\
\hline 6. AESF & 2,632 & 0,287 & 0,01 \\
\hline 7. DIBS & 1,141 & 0,093 & 0,257 \\
\hline \hline
\end{tabular}


The personal judgment about the achieved shape, softness, size, symmetry of the breasts exerts the strongest impact on the satisfaction with the new appearance. The abovementioned values prove the well-known fact that the level of satisfaction is strongly dependent on patient's subjective perception of the achieved desired outcome.

The second factor influencing the level of satisfaction is the opinion of a husband, family, relatives, friends and colleagues.

The third strongest influencing factor is the new appearance in a swimming suit.

The dynamics of satisfaction moves from overt, private, personal towards covert, public, open assessment of the new appearance. That kind of dynamics in the feeling of satisfaction is quite often assumed in hypotheses, however, it has very rarely been proven by empirical tests.

The impact level of the independent variables on the dependent variable is shown in Table 8 .

Table 8. Impact level of the independent variables on the confidence $(C)$

\begin{tabular}{||l|c|c|c||}
\hline \hline $\begin{array}{l}\text { Independent } \\
\text { variables }\end{array}$ & $\boldsymbol{t}$ & $\begin{array}{c}\text { Standardized } \\
\text { beta }\end{array}$ & $\mathbf{p}$ \\
\hline 1. AOSHVSS & 1,073 & 0,129 & 0,286 \\
\hline 2. LFA & $-1,995$ & 0,129 & 0,049 \\
\hline 3. FWW & 0,336 & 0,129 & 0,737 \\
\hline 4. FCWB & 0,514 & 0,082 & 0,609 \\
\hline 5. FCWN & 0,599 & 0,08 & 0,551 \\
\hline 6. AESF & 0,549 & 0,072 & 0,585 \\
\hline 7. DIBS & 3,236 & 0,317 & 0,002 \\
\hline \hline
\end{tabular}

Here the multiple correlation coefficient is $\mathrm{r}=0,576$ and the proportion of variation in the dependent variable is $\mathrm{r}^{2}=0,510$.

Statistical evidence shows that breast size is the most important factor influencing on personal confidence followed by breast shape, softness, and symmetry.

The above-mentioned parameters constitute only a part of the complex construct of confidence. More specifically, confidence is quite strongly influenced by the individual self-concept, too, as an internal model comprising various self-assessments.

\section{CONCLUSION}

It could be concluded that this investigation of the factors influencing on the levels of satisfaction with augmentation mammaplasty provided a valuable feedback for the surgeons. Obviously, the general assessment score of the surgical work is quite high.

In addition the results of the study show a significant correlation between the new physical image of the patients and their personal confidence.
And, as this paper illustrates, the overall levels of confidence and satisfaction of the patients have increased significantly after the surgery and that consequently leads to a higher quality of life.

\section{REFERENCES}

1. Aleksandrov, I. Effects of long-term motivation on the functioning of the individual in the process of rehabilitation to outpatient environment.- In: VI. National Congress of Psychology. Sofia, 2011.

2. Anderson, R. C., B. Cunningham, E. Tafesse, W. R. Lenderking. Validation of the breast evaluation questionnaire for use with breast surgery patients.- Plast. Reconstr. Surg., 118, 2006, No 3, 597-602.

3. Colakoglu, S., I. Khansa, M. S. Curtis, J. H. Yueh, A. Ogunleye, A. Haewyon, et al. Impact of complications on patient satisfaction in breast reconstruction.- Plast. Reconstr. Surg., 127, 2011, No 4, 1428-1436.

4. Handel, N., T. Cordray, J. Gutierrez, J. A. Jensen. A long-term study of outcomes, complications, and patient satisfaction with breast implants.Plast. Recontr. Surg., 117, 2006, No 3, 757-767.

5. Hölmich, L. R., V. B. Breiting, J. P. Fryzek, B. Brandt, M. S. Wolthers, K. Kjøller, et al. Long-term cosmetic outcome after breast implantation.- Ann. Plast. Surg., 59, 2007, No 6, 597-604.

6. Hunstad, J. P., L. S. Webb. Subfascial breast augmentation: a comprehensive experience.- Aesthetic Plast. Surg., 34, 2010, No 3, 365-373.

7. Kamburoglu, H. O., F. Ozgür. Postoperative satisfaction and the patient's body image, life satisfaction, and self-esteem: a retrospective study comparing adolescent girls and boys after cosmetic surgery.Aesthetic Plast. Surg., 31, 2007, 31, No 6, 739-745.

8. Klassen, A. F., A. L. Pusic, A. Scott, J. Klok, S. J. Cano. Satisfaction and quality of life in women who undergo breast surgery: a qualitative study.- BMC Women's Health, 9, 2009, 11.

doi: 10.1186/1472-6874-9-11.

9. Lipworth, L., K. Kjшller, L. R. Нцlmich, S. Friis, J. Olsen, R. McLaughlin, et al. Psychological characteristics of Danish women with cosmetic breast implants.- Ann. Plast. Surg., 63, 2009, No 1, 11-14.

10. Pusic, A. L., C. M. Chen, S. Cano, A. Klassen, C. McCarthy, E. D. Collins, et al. Measuring quality of life in cosmetic and reconstructive breast surgery: a systematic review of patient-reported outcomes instruments.- Plast. Reconstr. Surg., 120, 2007, No 4, 823-837.

11. Sabino, N. M., A. L. da Silva, E. B. Garcia, M. Freire, L. Ferreira. Quality of life and self-esteem after breast asymmetry surgery.- J. Aesthetic Surg., 27, 2007, No 6, 616-621.

12. Spear, S. L., C. V. Pelletiere, N. Menon. One-stage augmentation combined with mastopexy: aesthetic results and patient satisfaction.- Aesthetic Plast. Surg., 28, 2004, No 5, 259- 267. 